\title{
White paper on peanut allergy: treatment pathway
}

\author{
Ludger Klimek · Lars Lange · Lea Alexandra Blum · Felix Klimek · Katja Nemat • Imke Reese · Katharina Blumchen
}

Received: 4 October 2021 / Accepted: 6 October 2021 / Published online: 6 December 2021

(C) The Author(s) 2021

\begin{abstract}
Summary
Background Peanuts are a member of the legume family (botanical family Leguminosae) and peanut allergies are the most common cause of food anaphylaxis in many countries. The prevalence of peanut allergy is increasing.

Methods Experts from Germany and Austria performed a standardized literature search and published their consensus recommendations in a White Paper on Peanut Allergy, which this care pathway is based upon, thus, providing a comprehensive diagnosis and treatment algorithm.

Results The most important diagnostic key elements include a detailed clinical medical history, evidence of peanut-specific sensitization by means of skin prick
\end{abstract}

Supplementary Information The online version of this article (https://doi.org/10.1007/s40629-021-00195-1) contains supplementary material, which is available to authorized users.

\section{Klimek · F. Klimek}

Center for Rhinology and Allergology Wiesbaden,

Wiesbaden, Germany

\section{Lange}

Department of Pediatrics, St. Marien Hospital, GFO Clinics Bonn, Bonn, Germany

\section{A. Blum · K. Blumchen $(\bowtie)$}

Department of Pediatric and Adolescent Medicine, Allergology, Pneumology and Cystic Fibrosis, University Hospital Frankfurt, Goethe University Frankfurt, Frankfurt a. M., Germany

katharina.bluemchen@kgu.de

\section{K. Nemat}

Practice for Pediatric Pneumology/Allergology, Kinderzentrum Dresden (Kid), Dresden, Germany

\section{Reese}

Nutrition Counseling and Nutrition Therapy with Special Focus on Allergology, Munich, Germany testing and/or in vitro determination of the peanut (extract)-specific IgE and/or the molecular component diagnostics (most important Ara $\mathrm{h}$ 2-specific IgE, sometimes also Ara h1-, 3-, 6-, 8- and 9-specific IgE) as well as the gold standard, the doubleblind, placebo-controlled food challenge. The diagnostic algorithms were created for the following constellations: Suspected primary peanut allergy with a clear history of systemic immediate-type reaction, suspected primary peanut allergy with questionable symptoms, suspected secondary (possibly pollenassociated) peanut allergy with a history of solely oropharyngeal symptoms and incidental finding of sensitization and no peanut ingestion so far.

Conclusions After established diagnosis the standard of care is counseling to avoid peanut contact and prescription of emergency medications (oral antihistamines, oral steroids, inhaled $\beta 2$-agonists, injectable intramuscular epinephrine) as needed. Instruction on the use of these emergency medications should be provided. A preparation for oral immunotherapy (OIT) for 4 to 17 years old peanut allergic children/ adolescents has been recently approved by the regulatory authorities. OIT for peanut allergy shows high efficacy and an acceptable safety profile, improves quality of life, and health economic aspects. Thus it offers a therapeutic option for peanut allergic children and adolescents.

Keywords Ara h2-specific IgE • Oral food challenge · Diagnostic algorithm • Oral immunotherapy (OIT)

\section{Peanut allergy}

Compared to most other foods, peanut has a particularly high allergenic potential and can therefore reduce the quality of life ongoing of those affected [1]. Thus, it is important to have targeted diagnostics that 


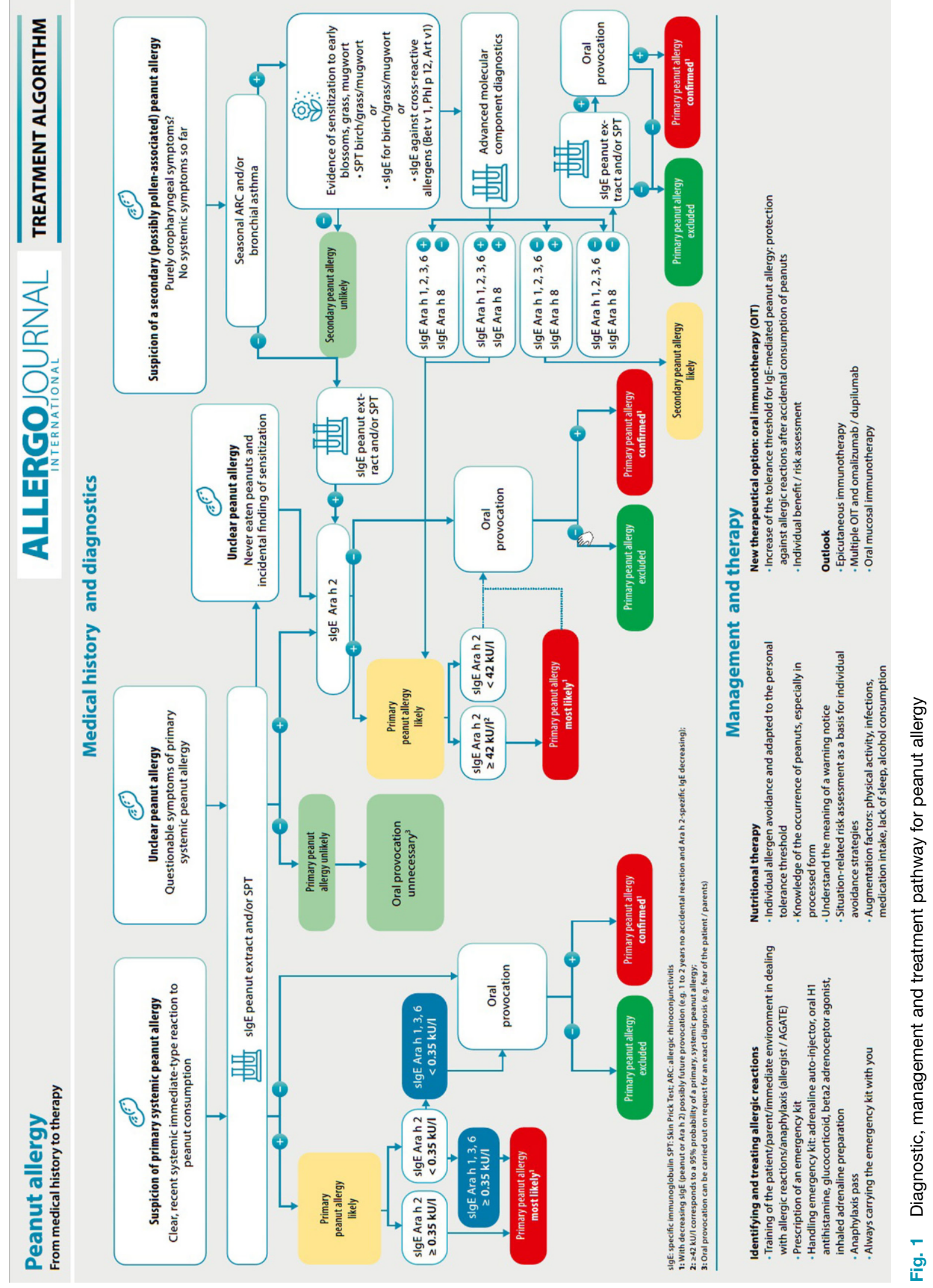


can safely confirm or exclude a primary peanut allergy. Peanut allergy management, in turn, aims to enable the patients to live well with their allergy in everyday life. In order to achieve this, knowledge of the medical history and diagnostics as well as management and therapy are essential. The treatment algorithm (Fig. 1; for full-size PDF see Supplementary Information) clearly summarizes everything relevant to peanut allergy.

\section{Medical history and diagnostics [2]}

The most important diagnostic key elements include a detailed clinical medical history, evidence of peanutspecific sensitization by means of skin prick testing and/or in vitro determination of the peanut (extract)specific IgE and/or the molecular component diagnostics as well as the gold standard, the double-blind, placebo-controlled food challenge. The flow diagram was created for the following constellations:

- Suspected primary peanut allergy with a clear history of systemic immediate-type reaction

- Suspected primary peanut allergy with questionable symptoms

- Suspected secondary (possibly pollen-associated) peanut allergy with a history of solely oropharyngeal symptoms

- Incidental finding during sensitization testing and no peanut ingestion so far.

\section{Management and therapy - nutritional therapy}

[3]

- Education about the occurrence of the offending food

- Align avoidance strategies individually according to the tolerance threshold

- Avoidance of peanuts-show the possibilities and limits of the food information regulation

- Maintain or restore quality of life through successful disease management in everyday life

- Meet the worries and fears of those affected and their families

- The risk for experiencing an allergic reaction and the severity of this reaction is dependent on the individual disposition.

- Possible augmentation factors: physical activity, infections, drug intake (e.g., non-steroidal anti-inflammatory drugs), lack of sleep, alcohol consumption

\section{Management and therapy-oral immunotherapy with Palforzia ${ }^{\circledR}[4]$}

- Patients aged 4-17 years with a confirmed diagnosis of primary peanut allergy

- Palforzia (Aimmune Therapeutics Ireland Limited, Dublin, Ireland) ${ }^{\circledR}$ is a powder (peanut protein as a defatted powder from Arachis hypogaea L., semen).

- Peanuts must continue to be avoided throughout therapy.

- The initial doses as well as each new dose level must be taken under medical supervision.

Funding Open Access funding enabled and organized by Projekt DEAL.

Conflict of interest L. Klimek reports grants and personal fees from Allergopharma, grants and personal fees from MEDA/ Mylan, personal fees from HAL, grants from ALKAbelló, grants and personal fees from LETI Pharma, grants from Stallergenes, grants from Quintiles, grants and personal fees from Sanofi, grants from ASIT biotech, grants from Lofarma, personal fees from Allergy Therapeutics, grants from AstraZeneca, grants from GSK, grants from Inmunotk, personal fees from Cassella med, outside submitted work; and membership: AeDA, DGHNO, German Academy of Allergology and Clinical Immunology, ENT-BV, GPA, EAACI. L. Lange reports on consultancy fees from Aimmune, DBV Technologies and Nestlé. He has given paid lectures for Aimmune, DBV Technologies, Nestlé and Nutricia. K. Blumchen reports personal fees from ThermoFisher Scientific; grants, personal fees, and nonfinancial support from Aimmune Therapeutics; grants, personal fees, and nonfinancial support from DBV Technologies; grants from Hipp GmbH; personal fees from Novartis; personal fees from Allergy Therapeutics; personal fees from HAL; personal fees from ALK; personal fees from Allergopharma; personal fees from Nutricia; personal fees from Nestle; personal fees from Bausch and Lomb, outside the submitted work. L.A. Blum, F. Klimek, K. Nemat and I. Reese declare that they have no competing interests.

Open Access This article is licensed under a Creative Commons Attribution 4.0 International License, which permits use, sharing, adaptation, distribution and reproduction in any medium or format, as long as you give appropriate credit to the original author(s) and the source, provide a link to the Creative Commons licence, and indicate if changes were made. The images or other third party material in this article are included in the article's Creative Commons licence, unless indicated otherwise in a credit line to the material. If material is not included in the article's Creative Commons licence and your intended use is not permitted by statutory regulation or exceeds the permitted use, you will need to obtain permission directly from the copyright holder. To view a copy of this licence, visit http://creativecommons.org/licenses/by/4.0/.

\section{References}

1. Lange L, et al. White paper on peanut allergy-part 1: epidemiology, burden of disease, health economic aspects. Allergo J Int. 2021; https://doi.org/10.1007/s40629-02100189-z.

2. Blum LA, et al. White paper on peanut allergy-part 2: diagnosis of peanut allergy with special emphasis on molecular component diagnostics. Allergo J Int. 2021; https://doi.org/10.1007/s40629-021-00190-6.

3. Reese I, et al. Nutrition therapy in peanut allergy. Allergo J Int. 2021; https://doi.org/10.1007/s40629-021-00176-4.

4. Blumchen K, et al. White paper on peanut allergy_part 3: Management and therapy of peanut allergy. Allergo J Int 2022;31(1); in press. 